The $B D J$ News section accepts items that include general news, latest research and diary events that interest our readers. Press releases or articles may be edited, and should include a colour photograph if possible. Please direct your correspondence to the News Editor, Arveen Bajaj at the BDJ, The Macmillan Building, 4 Crinan Street, London N19XW or by email to bdj@bda.org

\section{Memorial award reinstated}

The International Association for Dental Research (IADR) has announced the reinstatement of the IADR Isaac Schour Memorial Award. The award, which was discontinued in 1981 due to a lack of financial support, will now be fully funded through a donation from $\mathrm{Dr}$ Bernard G Sarnat, a former graduate student of Schour, and Rhoda G Sarnat, through the Sarnat Family Foundation. The donation will ensure the continuation of the award in perpetuity.

Funded at the same level as all IADR Distinguished Scientist Awards, the award will recognise outstanding scientific contributions in the anatomic sciences, including tissue engineering, tissue regeneration, and stem cell research as it relates to the oral, dental, or craniofacial complex. The first reinstated award, which will consist of a $\$ 2,000$ prize and a plaque, will be presented at the IADR General Session and Exhibition in New Orleans, March 21-24, 2007.

The IADR Isaac Schour Memorial Award was first established in 1967 to honor Schour, an early leader in international dental research and the 18th president of the IADR (1941-42). Schour was Professor of histology (1935-1964) at the University of Illinois College of Dentistry, where he was Dean from 1955 until his death in 1964 at the age of 64.

The annual award, which was international in scope, was originally presented to an individual who had made outstanding contributions in research or training, or both, in the field of anatomic sciences.

\section{Death notice}

It is with sadness that we report the recent death of the greatly admired and very popular Professor Robert Harkness of University College London.

\section{Dentists battle the elements}

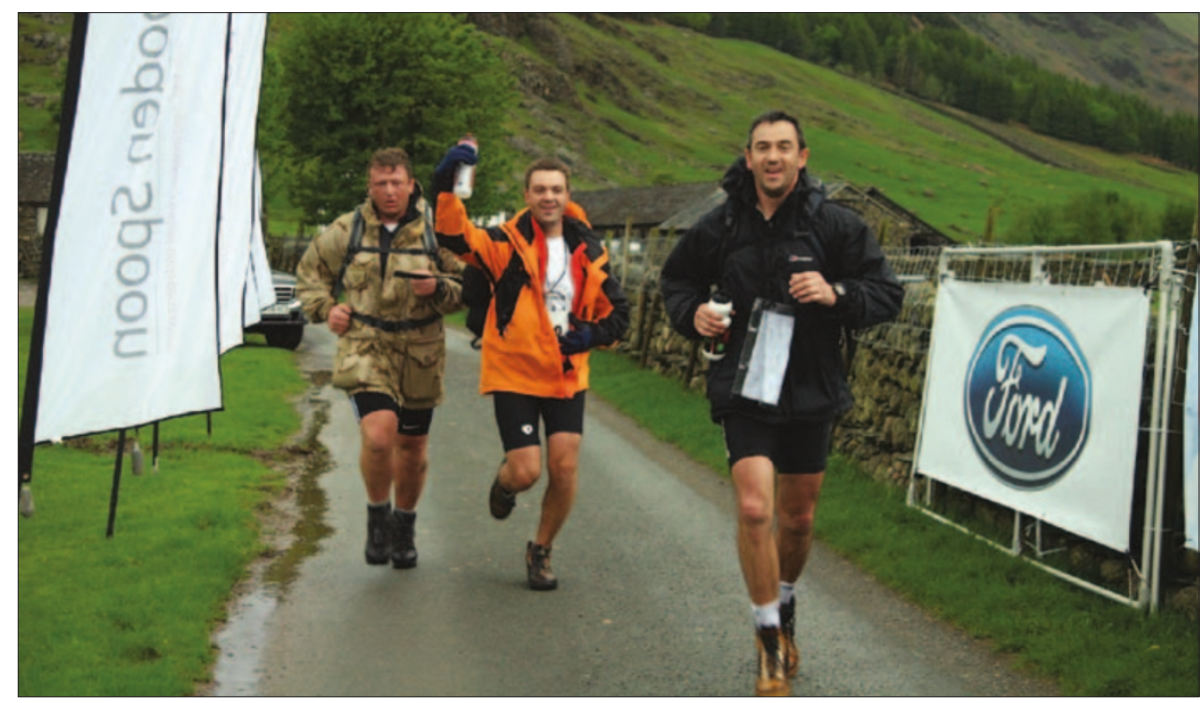

Left to right, Tony Sunderland, Mark Willings and Rob Sawyer at the finish

Dentists Mark Willings and Richard Graye raised $€ 6,000$ in aid of rugby's charity Wooden Spoon after competing in the tenth annual Ford Ranger Great Lakeland Challenge recently. The charity, who's patron is HRH The Princess Royal, aims to enhance the quality and prospect of life for children and young people in the United Kingdom who are disadvantaged either physically, mentally or socially.

Wakefield-based Mark, who teamed up with electrician Tony Sunderland and sales manager Rob Sawyer, also from Wakefield, canoed the length of Lake Windermere (10.5 miles), cycled 26 miles over England's steepest passes - Wrynose and Hard Knott - and climbed the mighty Scafell Pike (3,208 ft).

They were assisted by support driver Richard Graye, a dental surgeon from Huddersfield, who transported their clothing and equipment between the stages.

The objective was to complete all three elements of this unique triathlon consecutively, inside 12 hours. Calling themselves Willing, Fit and Able, the team finished an impressive sixth out of 28 participants, crossing the finish line in 9 hours and 2 minutes. "We were really pleased with our performance despite the awful weather and having to contend with strong headwinds and driving rain in the canoe and on the bikes, and were delighted to achieve our target of nine hours," said Mark.

The total sum pledged by the competitors - who included accountants, IT consultants, construction industry professionals, engineers, motor industry executives and teachers - was $€ 173,436.59$.

\section{Queen's birthday honours announced}

Figures from the dental community featured heavily in the Queen's birthday honours this year. CBEs went to Professor Cynthia Pine, Dean of Liverpool Dental School, Dr Hamish Wilson, until recently the head of the Primary Care Division of the Scottish Executive and Professor Simon Andrew Smail, Dean, School of Postgraduate Medical and Dental Education, Cardiff University for services to medicine.

An OBE was awarded to Professor Michael Lennon of the British Fluoridation Society. Recipients of MBEs included Sara Holmes, Head of the School of Dental Care Professionals at the University of Portsmouth, Derek Miles, the Chief Dental Equipment Technician at the University of Cardiff Dental School, Kevin Page, the Chair of the Institute of Maxillo-facial Prosthetists and Technologists. MBEs also went to Dr Philip Ratcliffe, a general dental practitioner from Wirral, for services to dentistry, John Rostron, a GDP from Liverpool MBE for services to education and Michael Selby who qualified BDS at Liverpool and was recognised for service to the community in Mollington \& Backford, Cheshire. 


\section{DIARY}

September

The British Society of Paediatric Dentistry

Annual Scientific Conference

'The Art \& the Science'

Venue: The Hilton, Leeds City

Date: 12-15 September 2006

www.bspd.co.uk/conf-2006.html

Moving to private practice

Venue: The Midland Hotel, Manchester

Date: 8 September 2006

www.bda-events.org

European Society for Oral Laser Applications/ Hellenic Society for Oral Laser Applications

1st Mediterranean Laser Congress

Venue: Hilton Hotel Rhodes Resort, Greece

Date: 21-23 September 2006

Email: esola2006@medacad.org

www.esola.at

FDI Annual World Dental Congress

Venue: Shenzhen, China

Date: 22-25 September 2006

Email:congress@fdiworldental.org

www.fdiworldental.org

October

The American Dental Association (ADA)

147th ADA Annual Scientific Session and

Marketplace Exhibition

Venue: Mandalay Bay Resort and

Convention Center, Las Vegas

Date: 16-19 October 2006

www.ada.org

Preparing for retirement

Venue: Cedar Court Hotel, Harrogate

Date: 6 October 2006

www.bda-events.org

Community Dental Services Group Annual

Presidential and Scientific meeting

Venue: Marriott Forest of Arden Hotel,

Birmingham

Date: 12-13 October 2006

www.bda-events.org

Hospitals Group Annual Presidential and

Scientific meeting

Venue: Portmeirion, North Wales

Date: 26-27 October 2006

www.bda-events.or

\section{November}

British Academy of Cosmetic Dentistry's (BACD) 2nd Annual Conference

Venue: Britannia International Hotel, London

Date: 16-17-18 November 2006

Email:info@bacd.com

www.bacd.com

\section{Guarding against oral cancer}

Routine dental check-ups are most cost effective guard against oral cancer, according to new collaborative research from the University of Sheffield, UCL Eastman Dental Institute and the Centre for Health Economics, University of York.

The new analysis suggests that dentists' routine screening of high-risk patients may be a practical proposition and appears to be cost-effective in relation to conventional benchmarks which are considered to provide good value for money in the NHS. The review is published in the latest issue of Health Technology Assessment, the international journal of the Health Technology Assessment program of the NHS for the UK.

However, lead researcher Professor Paul Speight, of the University of Sheffield's School of Clinical Dentistry, says the estimate assumes that treating precancerous lesions in the mouth lessens the chance that the lesions will become malignant. Professor Speight and his research colleagues, Mr Stephen Palmer (Centre for Health Economics, University of York), Dr David Moles and Professor Martin Downer (UCL Eastman Dental Institute) have cautioned, however, that a review of medical literature revealed that there is little evidence that this is the case. The consortium's analysis also depends heavily on how much the NHS would be willing to pay for both screening and treatments for oral cancer.

The team collected data on resources and costs in oral cancer treatment from two hospitals, as well as information from published studies and expert clinicians. They tested a variety of screening scenarios, from no screening at all to screening at routine visits to a doctor or dentist, on a hypothetical population of British people aged 40 and over.

The models suggest screening people ages 40 to 70 may be more cost-effective than screening those age 70 and older. Screening by doctors was only slightly more expensive than screening by dentists, despite the doctors' lack of specific training to identify oral lesions. The researchers suggest that doctors may catch more

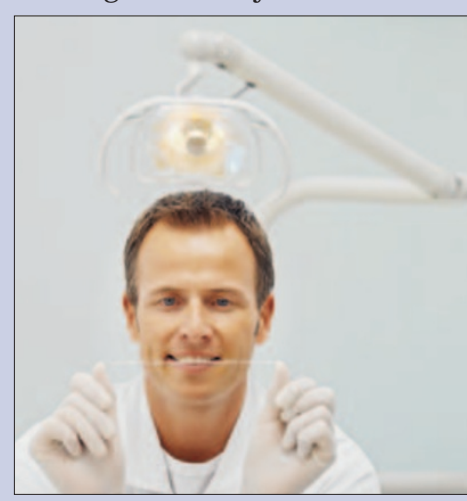
cancers because they see a bigger proportion of the population than their dental colleagues. Professor Speight said, "Most people do not realize they have oral cancer until the disease is well advanced, which can make treatment long and costly. There has been no improvement in survival rates among oral cancer patients for over four decades, and recent studies show that the incidence of the disease is increasing. One of the key ways we can try and reverse this trend is to improve detection of lesions while they are small, which can be achieved with maximum cost efficiency during routine check-ups."

\section{Pregnancy cravings with a difference}

Ice cream and pickled onions may be the pregnancy craving that many have heard about, but for women suffering from the eating disorder pica, cravings for soap, freezer frost, or even soil are more the order of the day. According to a study published in the May/June 2006 issue of General Dentistry, the Academy of General Dentistry's (AGD) clinical, peer-reviewed journal, pica combined with bulimia can have adverse effects on an individual's oral health during pregnancy and also can be hard to diagnose and treat during those nine months. The study reports that pica, usually a secretive behaviour, is a compulsive eating disorder in which sufferers have a constant appetite for non-nutritious substances, while bulimia is a condition in which patients overeat and then purge due to a fear of gaining weight. While the conditions' association and cause during pregnancy are not known, many suggest cultural and physiological factors are to blame. Others believe depression or iron and zinc deficiencies during pregnancy could be a factor.

"Eating disorders can cause serious erosion of the tooth's enamel, as well as sensitivity, thinning, and chipping," said AGD spokesperson Paula Jones, DDS, FAGD. "Dentists can detect the signs and provide patients with treatment options."

She added that while women often believe they should avoid dental care during pregnancy, it is important for those suffering from eating disorders to continue with their dental visits as many of those who suffer will not self-report the problem.

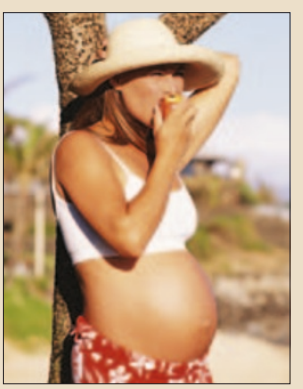




\section{Children benefit from new dental unit}

A modern multi-disciplinary dental care facility primarily for children has recently been launched in Liverpool. The new Oral Health Suite, based at the University of Liverpool Dental Teaching Hospital, comprises three new surgeries with facilities for conscious sedation which is particularly suited to children. This is specifically designed as an alternative to general anaesthetic to relax young patients with dental anxiety and improve their response to treatment.

The facility will also accommodate a diverse range of specialist dentistry including orthodontics for the treatment of children born with cleft lip and palate. A special quiet area away from the surgeries has been created so children can get advice on general oral hygiene and toothbrushing.

Dr Anne Field, Clinical Director at the University's Dental Hospital, commented, "The diversity of clinical services available will be of great benefit to children in Merseyside and the surrounding area."

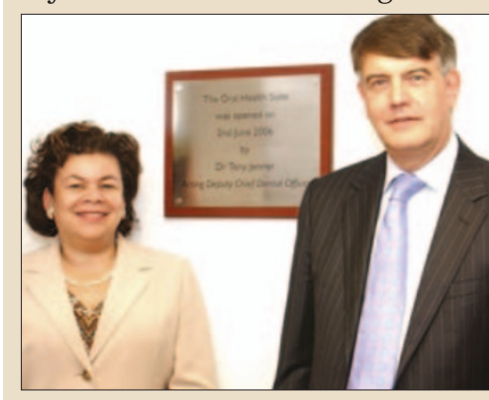

Professor Cynthia Pine, Dean of Dental Studies at the University (left) and Tony Jenner, Acting Deputy Chief Dental Office for the UK at the opening ceremony
As well as specialist treatment and teaching the unit will provide a focus for two important international research programmes that will benefit the wider community. Liverpool is already leading in diagnostic techniques such as Quantitative LightInduced Fluorescence (QLF). This programme, led by Professor Neil Pender and Professor Sue Higham, focuses on methods for the early detection and monitoring of the loss of minerals in teeth. Professor Alan Brook, newly appointed Professor of Child Dental Health is leading a new international programme on understanding and managing abnormalities that can occur in the development of teeth.

\section{Carers should not overlook oral health}

Caregivers are at risk of elevated plaque levels and increased gingival bleeding, according to a new study printed in the Journal of Periodontology. The study found that people under psychological or physical stress, as well as those with the conditions themselves, should not overlook their oral health.

The results from the study suggest that being a caregiver to relatives with dementia, hypercortisolemia (overproduction of cortisol) or stress were associated with elevated plaque levels and increased gingival bleeding in a study that examined adults aged 50 years and older.

The study indicates that the demanding task of caregiving, usually associated with increased stress, may be a risk factor for poor oral hygiene. These findings point out that stress may contribute to a disinterest in performing oral hygiene.

"We found that short term psychological stress was a risk indicator to elevated plaque levels and long term physical stress was a risk indicator to gingivitis," said Fernando N. Hugo, DDS and Faculty of Dentistry of Piracicaba, Brazil. "These findings support the health impact of psychosocial risk factors from chronic stress, which may lead to malfunction of some biological functions."

In the study, 230 individuals were evaluated, and almost 52 percent were caregivers. Caregivers of patients with dementia were examined because they represent a well-known group suffering from the impacts of chronic stress on human health and immune functions. "Flossing and brushing the teeth and gums had a protective effect against plaque and gingivitis," said Kenneth A. Krebs, DMD and AAP President. "That said, future research is needed to explore the relationship between stress and oral hygiene negligence."

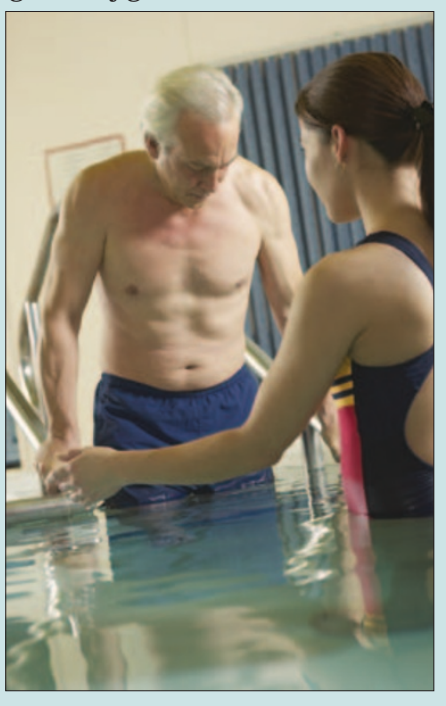

\section{Ultrasound may help regrow teeth}

A team of researchers from the University of Alberta has created technology to regrow teeth. Using low-intensity pulsed ultrasound (LIPUS), Dr Tarak El-Bialy from the Faculty of Medicine and Dentistry together with Dr Jie Chen and Dr Ying Tsui from the Faculty of Engineering have created a miniaturised system-on-a-chip that offers a non-invasive and novel way to stimulate jaw growth and dental tissue healing.

The wireless design of the ultrasound transducer means the miniscule device will be able to fit comfortably inside a patient's mouth while packed in biocompatible materials. The unit will be easily mounted on an orthodontic or "braces" bracket or even a plastic removable crown.

The team also designed an energy sensor that will ensure the LIPUS power is reaching the target area of the teeth roots within the bone. Currently, the research team is finishing the system-on-a-chip and hopes to complete the miniaturised device by next year.

"If the root is broken, it can now be fixed," said Dr El-Bialy. "And because we can regrow the teeth root, a patient could have his own tooth rather than foreign objects in his mouth."

The device is aimed at those experiencing dental root resorption, a common effect of mechanical or chemical injury to dental tissue caused by diseases and endocrine disturbances. Mechanical injury from wearing orthodontic braces causes progressive root resorption, limiting the duration that braces can be worn. This new device will work to counteract the destructive resorptive process while allowing for the continued wearing of corrective braces.

In a true tale of interdisciplinary work, Dr El-Bialy met Dr Chen at the University of Alberta's new staff orientation. After hearing about Chen's expertise in nanoscale circuit design and nano-biotechnology, ElBialy explained his own research and asked if Chen might be able to help produce a tiny ultrasound device to fit in a patient's mouth. The two collaborated and eventually along with Tsui received a grant from NSERC's "Idea to Innovation," program to expand on their prototype.

The researchers are currently working on turning their prototype into a market-ready model and expect the device to be ready for the public within the next two years.

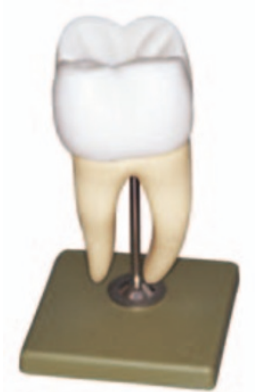




\section{Senior}

\section{academic honoured}

A renowned and highly respected senior dental academic has this month been honoured at the dental school with which he was closely associated throughout his professional life until his death in 2004.

Dr Henry Noble joined Glasgow Dental School as a student in 1942 and as a mark of the respect and affection in which he was held, a ceremony was held in the James Ireland Memorial Library at the School in May, during which a custombuilt oak display case, donated by his wife, Mrs Audrey Noble, and other members of Dr Noble's family, was presented.

The display case will house items belonging to the Henry Noble History of Dentistry Research Group (www.rcpsglasg. ac.uk/hdrg), a group founded by Dr Noble during his retirement. The evening also marked the opening of a new student computer cluster in the Dental School Library, which has doubled the number of terminals available to BDS students in the School. According to the University, as someone who was always ready to embrace IT and other technological advances, Dr Noble would surely have approved of this dual event held in his honour.

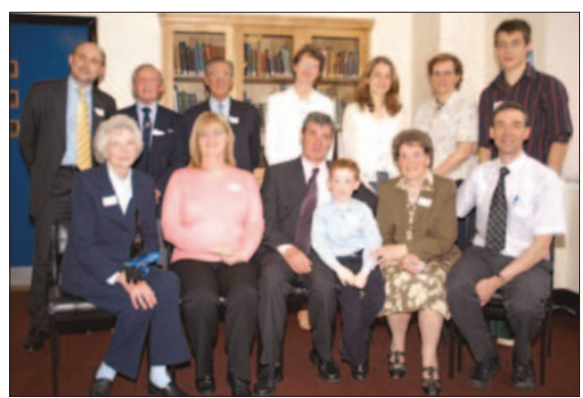

\section{Diabetics at greater risk of loosening teeth}

Individuals with diabetes run a greater risk than others of being afflicted with severe loosening of the teeth according to research at the Faculty of Odontology, Malmö University, Sweden.

Henrik Jansson's dissertation Studies on periodontitis and analyses of individuals at risk for periodontal diseases covered nearly 200 patients with type 2 diabetes, socalled adult onset diabetes. He found that as many as every fifth patient suffered from severe loosening of the teeth, periodontitis and that the occurrence of cardiovascular diseases was significantly higher among diabetics suffering from severe periodontitis. "This discovery is interesting because there has been a great deal of talk about the connection between cardiovascular disorders and periodontitis. But the underlying causes have not been clear. One hypothesis is that chronic inflammatory processes, in the gums, for instance, can influence mechanisms in other parts of the body as well," said Henrik Jansson, a specialist in periodontology and instructor at the Faculty of Odontology in Malmö. "Periodontitis is a chronic inflammation that arises in response to the natural flow of bacteria in the mouth. There is a genetic factor involved; the disease can be passed on from one generation to another," said Dr Jansson.

One major problem involving periodontitis is that the disease is not always noticeable. He added that if the disease is discovered in time, it is often sufficient to carry out a professional cleaning. On the other hand, if it has progressed further, surgery may be needed.

With the aim of preventing the disease, Dr Jansson would like to see better information targeting relevant risk groups and regular check-ups by a dentist or dental hygienist. "To minimize the risk of relapse it is also important to work on patient motivation, both during and following treatment," Dr Jansson points out

\section{New diploma for technicians approved}

The Faculty of General Dental Practice (UK), working with the Kent, Sussex and Surrey (KSS) Deanery, has been given the go-ahead by the General Dental Council (GDC) to progress a route to registration for clinical dental technicians (CDTs). There are currently no approved awards in clinical dental technology offered in the UK, however there are a significant number of dental technicians working in the UK today who hold qualifications in this field from the George Brown College in Toronto.

The new route to registration will allow those with George Brown awards to undertake extra training, provided through KSS, leading to an FGDP(UK) Diploma in Clinical Dental Technology.

The CDT is a new role that will be introduced to the dental team when the registers of dental care professionals open at the end of July. CDTs will be able to see edentulous patients without prior review by a dentist. Work is now underway to establish a process for the training and assessment of potential CDTs from this group. For further information or to register an interest in the diploma, please contact Sally Hunter, FGDP(UK) Development Officer, on 02078696766 or shunter@rcseng. ac.uk. 


\section{Nominate your teacher}

The Dental Defence Union (DDU) is asking students and vocational dental practitioners (VDPs) to nominate the teachers or trainers who have inspired them for the DDU education awards 2006.

Three awards are up for grabs this year - Dentist Teacher of the year, VT Trainer of the year and, for the first time, dental care professional (DCP) Teacher of the year. Finalists will each be awarded $£ 250$ and in addition, the overall winners in each category will receive $£ 1,000$ towards the cost of educational materials for their schools or VT schemes. Nominations must be received by 31 July, with the awards ceremony taking place on 7 November in central London.

Rupert Hoppenbrouwers, head of the DDU, said, "I'm sure all dental professionals can remember a teacher or trainer who has had a positive influence on them in their dental career and the DDU educational awards, which are now in their fourth year, are designed to recognise these unsung heroes of the dental profession. In previous years the awards have identified and rewarded some outstanding dental educators,

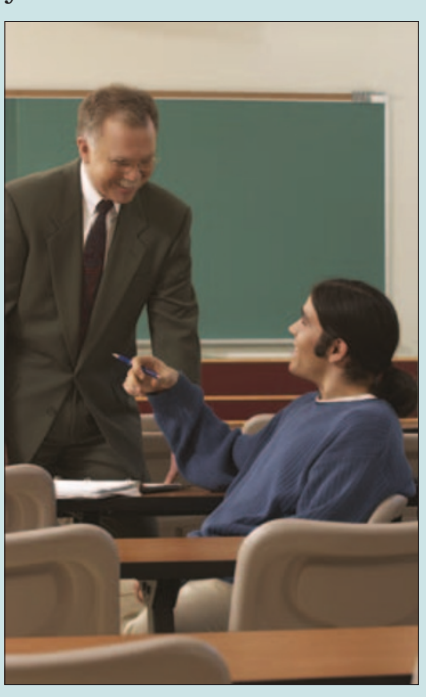
who have the ability to inspire and inform their students in equal measure and we are confident this year will be no exception."

Students and VDPs in the UK and Ireland can nominate a teacher or trainer by completing a nomination form, which is then reviewed by the DDU and a panel of judges. Forms are available on the DDU website www.the-ddu.com or from DDU dental liaison manager. Students and VDPs who submit an entry will be entered into a prize draw to win an iPod.

The winner in the Dentist Teacher and DCP teacher categories will be chosen following a presentation by finalists at the awards ceremony, while in the VT Trainer category, a panel of judges will decide the winner in advance of the ceremony. Awards will be judged across a number of criteria, including knowledge of the subject, enthusiasm and ability to motivate.

\section{Cancer treatment drugs may cause jawbone to rot}

Breast cancer patients, individuals at risk for osteoporosis, and individuals undergoing certain types of bone cancer therapies are at risk of developing osteonecrosis of the jaws (a rotting of the jaw bones), according to a study featured in Academy of General Dentistry's (AGD) journal.

The report says that these individuals often take drugs that contain bisphosphonates, a family of drugs used to prevent and treat osteoporosis, multiple myeloma, Paget's disease (bone cancers), and bone metastasis from other cancers. These drugs can bond to bone surfaces and prevent osteoclasts (cells that breakdown bone) from doing their job.

"Healthy bones constantly rebuild themselves," explains co-author of the report Sally-Jo Placa, DMD, MPA. "However, since the jawbones have rapid cell turnover, they can fail to heal properly in patients taking any of the bisphosphonate drugs. Patients need to be aware of the possibility of complications from dental surgery or extractions." Since these drugs linger in the bone indefinitely, they may upset the cell balance in how the jaws regenerate and remove unhealthy bone, she adds. In their report, the authors refer to the case of a woman who received bisphosphonate therapy intravenously to treat metastatic breast cancer. She then developed osteonecrosis in her upper and lower jaws following tooth removal. "This type of osteonecrosis has been occurring since the advent of these drugs," explains co-author Wellington S. Tsai, DMD. "At this time osteonecrosis as a result of bisphosphonate therapy has no treatment." The authors recommended that patients scheduled to receive bisphosphonate therapy should visit a dentist or an oral surgeon so problematic teeth can be treated prior to the start of therapy.

\section{Award for mouth cancer website}

The Mouth Cancer Foundation has won an award for its website, www.mouthcancerfoundation.org. The Cancer on the Internet Award 2006 will be presented at the 3rd International Conference on Cancer on the Internet in July in Washington DC. The awards are the original initiative of the European School of Oncology and this year it is made in exclusive partnership with Novartis Oncology. Dr Vinod K Joshi, Founder of the Mouth Cancer Foundation, said, "The award is fantastic news and will enable further improvements in our service. The website's success is also a tribute to the over 1,000 members of the online support group who have helped create a 24/7 caring community that reaches out to frightened newcomers, sharing stories and experiences with honesty, compassion, and a level of understanding that is unsurpassed."

This announcement comes as the Mouth Cancer Foundation is about to launch a new website specifically for the $10 \mathrm{~K}$ walk that will take place during Mouth Cancer Awareness Week in November. Further

\begin{tabular}{|l|l} 
CANCER & $\begin{array}{l}\text { information about } \\
\text { the mouth cancer } \\
\text { walk and new web- } \\
\text { site will soon be } \\
\text { available at www. } \\
\text { mouth can cer- } \\
\text { foundation.org. } \\
\text { AWARD INTEN }\end{array}$
\end{tabular}

\section{Charity to close}

The Leeds Foundation for Oral Research has recently announced it is to close.

It was originally started in 1988 by Professors Martin Curzon and Michael Kowolik, of Leeds, to provide money to encourage and support young dentists to take up postgraduate studies in paediatric dentistry and the care of people with special needs.

Tuition fellowships, research grants and travel bursaries have been awarded each year until 2006. In the past, there were few if any Government funded training posts for these specialities, but there has been a considerable change in the funding of training in these two dental specialities from central Government funds. Therefore the rationale for the charity no longer exists and the decision has been made close.

Over the life of the charity some $£ 75,000$ has been raised and used to support 37 young dentists. A number of these people have now attained Consultant status within the NHS as well as in the Community Dental Services in paediatric dentistry and the care of people with special needs. 